\title{
Knowledge of Emergency Management of Avulsed Teeth Among General Dentists in Kathmandu
}

\author{
Upadhyay S, Rokaya D, Upadhyaya C
}

\author{
Dental Department \\ Dhulikhel Hospital - Kathmandu University Hospital \\ Dhulikhel, Kavre, Nepall \\ Corresponding Author \\ Sumita Upadhyay \\ Dental Department \\ Dhulikhel Hospital - Kathmandu University Hospital \\ Dhulikhel, Kavre, Nepal I \\ Email: sumitadhungana@yahoo.com
}

\section{Citation}

Upadhyay S, Rokaya D, Upadhyaya C. Knowledge of Emergency Management of Avulsed Teeth Among General Dentists in Kathmandu. Kathmandu Univ Med J 2012;38(2):37-40.

\begin{abstract}
Background

An avulsed permanent tooth is one of the most emergency situations in dentistry. Dentists handling the situation should have adequate knowledge in this field.

Objective

To assess the level of knowledge of emergency management of avulsed teeth among general dentists in Kathmandu.

\section{Methods}

A questionnaire containing 10 close ended questions about emergency management of avulsed teeth was distributed among 102 general dental practitioners working in different private dental hospitals and clinics of Kathmandu. The dental hospital and clinics were randomly selected. This cross sectional study was conducted between January 2012 to February 2012.
\end{abstract}

\section{Results}

Among the studied group, almost all of the participants, 98(96.1\%) said that an avulsed permanent tooth cannot be replanted in all cases. Majority of them, 63 $(61.8 \%)$ said that the critical time for the replantation is within 20 minutes. General dentists of Kathmandu did not have adequate knowledge about emergency management of avulsed teeth.

\section{Conclusion}

An education program should be conducted to increase the knowledge of general dentists in the management of traumatic injuries to teeth.

\section{KEY WORDS}

Avulsion, emergency, general dentists, replantation

\section{INTRODUCTION}

Tooth avulsion (exarticulation /total luxation) implies total displacement of tooth out of its socket. Maxillary central incisors are the most frequently avulsed teeth. ${ }^{1}$ Though infrequent (0.5 to $3 \%)$, avulsion of permanent teeth is the most serious of all dental injuries. ${ }^{1}$ The prognosis depends on the measures taken at the place of accident or the time immediately after the avulsion. ${ }^{2,3}$

Treatmentobjective foravulsed permanentteeth istoreplant as soon as possible and then to stabilize the replanted tooth in its anatomically correct position to optimize the healing of periodontal ligament and neurovascular supply while maintaining the esthetics and functional integrity except when replanting is contraindicated by the child's stage of dental development (risk for ankylosis where considerable alveolar growth has to take place); compromising medical condition; or compromised integrity of the avulsed tooth or supporting tissues. ${ }^{4}$

Here, the dentist's knowledge in the emergency management of avulsed tooth is very important. There is no any published data regarding knowledge of dentists in this field. Purpose of this study was to evaluate the knowledge of general dentists working in Kathmandu about the management of avulsed teeth. 


\section{METHODS}

A cross-sectional study was conducted among general dentists working in different private dental hospitals and clinics of Kathmandu. The time period of the study was between January 2012 to February 2012. The private dental hospitals and clinics of Kathmandu were randomly selected. A total of 102 participants who had completed B.D.S (Bachelor of Dental Surgery) degree were randomly selected from those hospitals and clinics, those who willing to participate were only included. A questionnaire was distributed among them which contained 10 close ended questions (multiple choice questions). They were asked to complete the questionnaire in front of the investigator. Confidentiality was maintained as it did not require name and contact number of the participants. Data were entered into SPSS 11.5. Descriptive analysis was carried out to assess the frequency.

\section{RESULTS}

The existing level of knowledge of general dentists about emergency management of avulsed teeth is depicted in table 1. Among the studied group, almost all of the participants, 98(96.1\%) said that an avulsed permanent tooth cannot be replanted in all cases. Majority of them, $63(61.8 \%)$ said that the critical time for the replantation is within 20 minutes, 38 (37.3\%) said it to be 20 to 60 minutes and a very less $1(1 \%)$ said it is one to two hours.

More than half of the participants i.e. 61 (59.8\%) chose Hank's balanced salt solution as an optimal storage media, 32 (31.4\%) chose patient's saliva, 5 (4.9\%) milk, 3 (2.9\%) saline solution and the least $1(1 \%)$ chose tap water.A very high number of dentists i.e. 84 (82.4\%) thought that the treatment of an avulsed tooth is not same in case of short or prolonged extra alveolar dry time whereas, 18 (17.6\%) thought that it to be same.

For the type of splint, 65 (63.7\%) suggested that rigid splint should be used and $37(36.3 \%)$ suggested the flexible splint. Higher number of participants $45(44.1 \%)$ chose longer splinting duration as six weeks, 37 (36.3\%) as four weeks and $20(19.6 \%)$ as two weeks. Calcium hydroxide as an intra-canal medicament was suggested by 70 (68.6\%), zinc oxide eugenol by $20(19.6 \%)$ and antibiotic paste by $9(8.8 \%)$ of the dentists. $3(2.9 \%)$ were not sure about the medicament.

When asked about the prognosis, only 12 (11.8\%) participants said that the teeth with open apex has better prognosis while $90(88.2 \%)$ said that teeth with closed apex has better prognosis. Majority of them i.e. 70 (68.6\%) thought that primary teeth should be replanted and 32 (31.4\%) thought that it should not. A very high number of the dentists i.e. 93 (91.2\%) had never attended any education program regarding management of traumatic injuries to teeth while only a very less of them, 9(8.8\%) said that they had attended.

\section{DISCUSSION}

This study provided baseline information about existing level of knowledge of emergency management of teeth avulsion among the dentists in Kathmandu.

A very high percentage of participants (96.1\%) correctly reported that avulsed tooth cannot be replanted in all cases. Tooth cannot be replanted in cases of extensive caries, severe root damage and in cases with advanced periodontal disease. However in most situations, replantation of avulsed tooth can be performed even with a dubious prognosis, where the tooth is considered as a temporary restoration. Until such time, a definitive treatment planning and specialist consultation can be carried out. ${ }^{1}$

For the question regarding critical time for the replantation, $61.8 \%$ of the dentists responded that it was within 20 minutes while $37.3 \%$ suggested $20-60$ minutes. An avulsed permanent tooth should be replanted as soon as possible. The risk of ankylosis increases significantly with an extra oral dry time of 20 minutes. ${ }^{4}$ If the tooth cannot be replanted within five minutes it should be stored in a medium that will maintain vitality of periodontal ligament fibers. ${ }^{2,5}$

It was encouraging to know that $59.8 \%$ of the dentists chose Hank's balanced salt solution (HBSS) as the storage media for an avulsed tooth. Guidelines given by International Association for Dental Traumatology also suggests HBSS as storage media., ${ }^{2,3}$ Optimal storage media in order of preference are: Viaspan (a specialized tissue culture medium), Hank's balanced salt solution (HBSS), cold milk, patient's saliva, saline solution, water. ${ }^{1,6,7}$ Though Viaspan and HBSS has been found to be better media for storage due to their ability to maintain the viability of periodontal ligament cells for longer period of time than other media, cost factor and availability creates a barrier for their use.

Only $4.9 \%$ of the dentists chose milk as the storage media whereas $31.4 \%$ preferred patient's saliva. Studies have found that cold fresh milk is a good tooth storage media. ${ }^{8}$ Although water is detrimental to cell viability due to its low osmolality and long term storage (i.e more than 20 minutes) in water has an adverse effect on periodontal ligament healing, it is better choice than dry storage. ${ }^{1}$

For the question regarding the treatment of an avulsed tooth before replantation; in case of short or prolonged extra alveolar dry time, $82.4 \%$ said that it is not same for both cases. In teeth with prolonged extra alveolar periods, where periodontal ligament can be assumed as necrotic, it has been suggested that root surface be treated with fluoride solution ( $2.4 \%$ sodium fluoride phosphate acidulated at $\mathrm{pH}$ 5.5) for 20 minutes prior to replantation. Prior to this, the necrotic periodontal ligament is removed with a scaler. ${ }^{1}$ The incorporation of fluoride ions in the cementum layer has been found to yield root surface resistant to resorption. ${ }^{9}$ Further, if the tooth has been dry for more than 60 minutes before replantation, root 
Table 1. Knowledge level of general dentists.

\begin{tabular}{|c|c|c|c|c|}
\hline & & & Frequency & Percentage \\
\hline \multirow[t]{3}{*}{ Q.1 } & \multicolumn{4}{|c|}{ Can an avulsed permanent tooth be replanted in all cases? } \\
\hline & a. & Yes & 4 & 3.9 \\
\hline & b. & No & 98 & 96.1 \\
\hline \multirow[t]{5}{*}{ Q.2 } & \multicolumn{4}{|c|}{ What is the critical time for the replantation of an avulsed tooth? } \\
\hline & a. & Within 20 mins & 63 & 61.8 \\
\hline & b. & $20-60$ mins & 38 & 37.3 \\
\hline & c. & 1-2 hour & 1 & 1.0 \\
\hline & d. & Not sure & 0 & 0 \\
\hline \multirow[t]{6}{*}{ Q.3 } & \multicolumn{4}{|c|}{ What is the optimal storage media? } \\
\hline & a. & Hank's balanced salt solution & 61 & 59.8 \\
\hline & b. & Milk & 5 & 4.9 \\
\hline & c. & Patient's saliva & 32 & 31.4 \\
\hline & d. & Saline solution & 3 & 2.9 \\
\hline & e. & Tap water & 1 & 1.0 \\
\hline
\end{tabular}

Q.4 Is the treatment of an avulsed tooth before replantation same in case of short or prolonged extra alveolar dry time?

$\begin{array}{rrrr}\text { a. } & \text { Yes } & 18 & 17.6 \\ \text { b. } & \text { No } & 84 & 82.4\end{array}$

Q.5 Type of splint used is

\begin{tabular}{|llll|}
\hline a. & Rigid & 65 & 63.7 \\
\hline b. & Flexible & 37 & 36.3 \\
\hline c. & Anyone & 0 & 0 \\
\hline d. & Not sure & 0 & 0 \\
\hline & Splinting period is for & & \\
\hline a. & Two weeks & 20 & 19.6 \\
\hline b. & Four weeks & 37 & 36.3 \\
\hline c. & Six weeks & 45 & 44.1 \\
\hline d. & Not sure & 0 & 0 \\
\hline
\end{tabular}

Q.7 What is the intra-canal medication used during root canal treatment?

\begin{tabular}{|llll|}
\hline a. & Zinc oxide eugenol & 20 & 19.6 \\
\hline b. & Calcium hydroxide & 70 & 68.6 \\
\hline c. & Antibiotic paste & 9 & 8.8 \\
\hline d. & Not sure & 3 & 2.9 \\
\hline Q.8 & Which one has better prognosis? & & \\
\hline & a. $\quad$ Open apex (immature tooth) & 12 & 11.8 \\
\hline b. & Closed apex (mature tooth) & 90 & 88.2 \\
\hline
\end{tabular}

Q.9 Should primary tooth be replanted?

$\begin{array}{llll}\text { a. } & \text { Yes } & 70 & 68.6 \\ \text { b. } & \text { No } & 32 & 31.4\end{array}$

Q.10 Have you ever attended any education program regarding management of traumatic injuries to teeth?
a. Yes
b. No
9
93

8.8

canal treatment may be carried out extra-orally prior to replantation. ${ }^{3}$

After replantation, an avulsed permanent tooth should be splinted. A splinting technique should allow physiologic movement of the tooth during healing. So, a flexible splint should be used. ${ }^{10}$ The result was quite unsatisfying as 63.7 $\%$ informed that they use rigid splint for avulsed tooth and $36.3 \%$ said that flexible splint should be used.

A very high number of the dentists preferred splinting for longer duration as $44.1 \%$ of them suggested that splinting period should be six weeks. $36.3 \%$ suggested it to be four weeks and a low percentage, $19.6 \%$ correctly said that it should be for two weeks. International Association for Dental Traumatology (IADT) suggested up to two weeks splinting for an avulsed tooth decrease the risk for ankylosis. $^{1-3}$ 
Calcium hydroxide as an intracanal medicament during root canal treatment was suggested by $68.6 \%$ of the dentists. Calcium hydroxide is recommended for intracanal medication for up to one month followed by root canal filling, or obturation can be carried out when an intact lamina dura can be visualized radiographically. ${ }^{11}$ It is generally agreed that calcium hydroxide has a beneficial effect on the outcome because of its antibacterial properties, ability to dissolve necrotic tissues and its ability to prevent or control inflammatory resorption. ${ }^{12,13}$ Ledermix (corticosteroid antibiotic intra-canal paste) has also been proposed following pulp extirpation as an intracanal medicament. The anti-inflammatory and antibacterial actions may decrease root resorption by directly inhibiting resorptive cells. ${ }^{14}$ So far, no human clinical studies have compared the effectiveness of ledermix and calcium hydroxide as an intra-canal medicament.

A very high percentage (68.6\%) of dentists thought that an avulsed primary tooth should be replanted which was quite dissatisfying. To prevent further injury to developing successor, an avulsed primary tooth should not be replanted..$^{4,15}$

About the prognosis of tooth, an alarming number of dentists $(88.2 \%)$ thought that closed apex has better prognosis than the tooth with open apex which is exactly opposite. An immature (open apex) tooth has the potential to establish revascularization when there is a minimum of a $1.0 \mathrm{~mm}$ apical opening. ${ }^{16}$

\section{REFERENCES}

1. Andreasen JO, Andreasen FM, Andreasen L. Textbook and color atlas of traumatic injuries to teeth. 4th ed. Blackwell Munksgaard; 2007.

2. Flores MT, Andersson L, Andreasen JO, Bakland LK, Malmgren B, Barnett $F$ et al. Guidelines for the management of traumatic dental injuries II. Avulsion of permanent teeth. Dent Traumatol 2007; 23:130-6.

3. Andersson L, Andreasen JO, Day P, Heithersay G, Trope M, DiAngelis AJ et al. International Association of Dental Traumatology guidelines for the management of traumatic dental injuries: 2. Avulsion of permanent teeth. Dental Traumatol 2012; 28:88-96.

4. American Academy of Pediatric Dentistry. Guideline on management of Acute Dental trauma. Pediatr Dent 2011;33(2):222-228.

5. Sigalas E, Regan JD, Kramer PR, Witherspoon DE, Opperman LA. Survival of human periodontal liament cell in media proposed for transport of avulsed tooth. Dent Traumatol 2004;20:21-8.

6. Barrett EJ, Kenny DJ. Avulsed permanent teeth: review of the literature and treatment guidelines. Endod Dent Traumatol 1997;13:153-63.

7. Troupe M, Friedman S. Periodontal healing of replanted dog teeth stored in Viaspan, milk and Hank's balanced salt solution. Endod Dent Traumatol 1992;8:183-8.

8. Oikarinen KS, Seppa ST. Effect of preservation media on proliferation and collagen biosynthesis of periodontal ligament fibroblasts. Endod Dent Traumatol 1987;3:95-9.

9. Shulman LB, Gedalia I, Feingold RM. Fluoride concentration in root surfaces and alveolar bone of fluoride immersed- monkey incisors three weeks after replantation. J Dent Res 1973;52:1314-6.
Furthermore, studies have found that pretreatment of immature tooth with topical doxycycline before replantation will double the chance of revascularization..$^{17,18}$ On the other hand, a mature tooth (ie. closed apex or apical opening $<1$ $\mathrm{mm}$ ) has little or no chance of revascularization. ${ }^{4}$

Reviewing all these, it seems that the general dentists of Kathmandu do not have adequate knowledge regarding management of avulsed teeth. It was surprising to see that $91.2 \%$ of the dentists had never attended any education program regarding emergency management of avulsed teeth. This explains the reason of insufficient knowledge in this field. Education programme about emergency management of avulsed teeth to the general dentists along with recent guidelines will contribute to the increase in the standard of care to the needy people.

The year of working experience of dentists was not recorded in this study. Knowledge of management of the dentist may be higher in those with greater duration of working experience and low in newly graduated dentists. This may be the limitation of the present study.

\section{CONCLUSION}

The general dentists of Kathmandu do not have adequate knowledge of emergency management of avulsed teeth. As management of avulsed teeth is one of the emergency situations in dentistry, they are in need of the education program in this field.

10. Yanxiang Zhao, Yi Gong.Knowledge of emergency management of avulsed teeth: a survey of dentists in Beijing, China. Dent Traumatol 2010; 26:281-284.

11. Turkistani J, Hanno A. Recent trends in the management of dentoalveolar traumatic injuries to primary and young permanent teeth. Dental Traumatol 2011;27:46-54.

12. Lengheden A, Blomlof L, Lindskog S. Effcet of delayed calcium hydroxide treatment on periodontal healing in contaminated replanted teeth. Scand J Dent Res 1991;99:147-153.

13. Kawashima N, Wadachi R, Suda H, Yeng T, Parahos P. Root canal medicaments. Int Dent J 2009;59:5-11

14. Chappuis V, Von Arx T. Replantation of 45 avulsed permanent teeth: a 1- year follow up study. Dent Traumatol 2005;21:289-296.

15. Flores MT. Traumatic injuries in the primary dentition. Dent Traumatol 2002;18:287-98.

16. Kling $M$, Cvek $M$, Mejare I. Rate of predictability of pulp revascularization in therapeutically reimplanted permanent incisors. Endod Dent Traumatol 1986;2(3):83-9.

17. Cvek M, Cleaton Jones P. Effect of topical application of doxycycline on pulp revascularization and periodontal healing in reimplanted monkey's incisors. Endod Dent Traumatol 1990;6:170-6.

18. Ritter ALS, Ritter AV, Murrah V, Sigurdsson A, Trope M. Pulp revascularization of immature after treatment with minocycline and doxycycline assessed by laser Doppler flowmetry, radiography and histology. Dent Traumatol 2004;20:75-84. 